NASA Technical Memorandum 102459

AIAA-90-0715

\title{
Atomic Hydrogen as a Launch Vehicle Propellant
}

Bryan A. Palaszewski

Lewis Research Center

Cleveland, Ohio

Prepared for the

28th Aerospace Sciences Meeting

sponsored by the American Institute of Aeronautics and Astronautics

Reno, Nevada, January 8-11, 1990

AUNCH VEHICLE PROPFLLANT HYROGFN

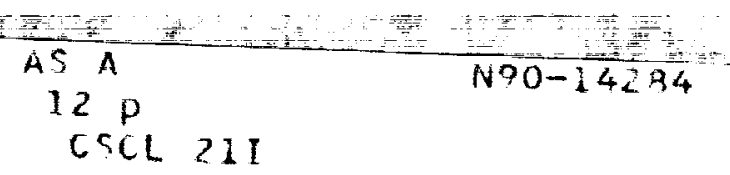

$\begin{array}{ll}\text { Unclas } \\ 03 / 20 & 0254510\end{array}$ 


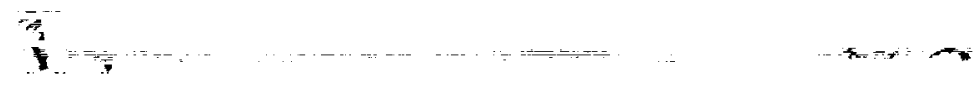


ATOMIC HYDROGEN AS A LAUNCH VEHICLE PROPELLANT

Bryan A. Palaszewski *

National Aeronautics and Space Administration

Lewis Research Center

Cleveland, Ohio 44135

Abstract

An analysis of several atomic hydrogen launch vehicles was conducted. A discussion of the facilities and the technologies that would be needed for these vehicles is also presented. The Gross Liftoff Weights (GLOW) for two systems were estimated; their specific impulses $\left(I_{s p}\right)$ were 750 and 1500 $1 b_{\mathrm{f}}-\mathrm{s} / 1 \mathrm{~b}_{\mathrm{m}}$. The atomic hydrogen launch vehicles were also compared to the currently planned Advanced Launch system design concepts. Very significant GLOW reductions of 52 to 85 percent are possible over the Advanced Launch system designs. Applying atomic hydrogen propellants to upper stages was also considered. Very high $I_{s p}$ (greater than $\left.750 \quad 1 b_{f}-s / 1 b_{m}\right)$ is needed to enable a mass savings over advanced oxygen/hydrogen propulsion.

Associated with the potential benefits of high-I atomic hydrogen are several challenging problems. Very high magnetic fields are required to maintain the atomic hydrogen in a solid hydrogen matrix. The magnetic field strength has been estimated to be 30 kilogauss (3 Tesla). Also the storage temperature of the propellant is 4 $K$. This very low temperature will require a large refrigeration facility for the launch vehicle. The design considerations for a very high recombination rate for the propellant are also discussed. A recombination rate of $210 \mathrm{~cm} / \mathrm{s}$ is predicted for atomic hydrogen. This high recombination rate can produce very high acceleration for the launch vehicle. Unique insulation or segmentation to "inhibit" the propellant may be needed to reduce its recombination rate.

\section{Nomenclature}

AFAL Air Force Astronautics Laboratory

ALS Advanced Launch system

BECO Booster Engine cut off

GLOW Gross Liftoff weight

HEDM High-Energy Density Materials

IUS Inertial Upper stage

$I_{s p} \quad$ Specific Impulse $\left(1 b_{f}-s / 1 b_{m}\right)$

JPL Jet Propulsion Laboratory

LEO Low Earth orbit
MECo Main Engine cut off

$\begin{array}{ll}M_{\mathbf{r}} & \text { Final Mass }(\mathrm{kg}) \\ \mathrm{M}_{0} & \text { Initial Mass }(\mathrm{kg})\end{array}$

NASA National Aeronautics and Space Administration

$\mathrm{O}_{2} / \mathrm{H}_{2} \quad$ Oxygen/Hydrogen

$\mathrm{O}_{2} / \mathrm{RP}-1$ Oxygen/Kerosene

STS Space Transportation system

Greek symbols

$\Delta V \quad$ Velocity Change $(\mathrm{km} / \mathrm{s})$

\section{Introduction}

In the development of NASA advanced launch vehicle designs, the need for increased payload delivery to orbit, increased reliability and reduced launch cost are crucial considerations. New technologies are being studied for the new vehicles such as the Advanced Launch System and the shuttlec (Refs. 1, 2, 3 and 4). These technologies includes lightweight tankage and structures, avionics, aerothermodynamics, automated production facilities, operations and rocket engines.

Additional performance increases will be possible with the use of high-energy propellant combinations. Both increases in the propellant $I_{s p}$ and increases in the propellant density are methods of improving the launch vehicle's performance. Many possible propellant combinations that can produce high $I_{\mathrm{kp}}$ are being studied both experimentally and theoretically. These studies are underway as part of the United states Air Force High Energy Density Materials (HEDM) Program (Ref. 5) and the NASA-Lewis Research Center Advanced Concepts Program.

one propellant that can provide increased $I_{s p}$ is atomic hydrogen. In this paper, the potential benefits and the technology advancements that are required for the successful use of atomic hydrogen as a propellant are discussed. Using atomic hydrogen will require new propellant production and storage facilities. These new facility and production requirements must be contrasted with the significant performance capability of the new propellant. 


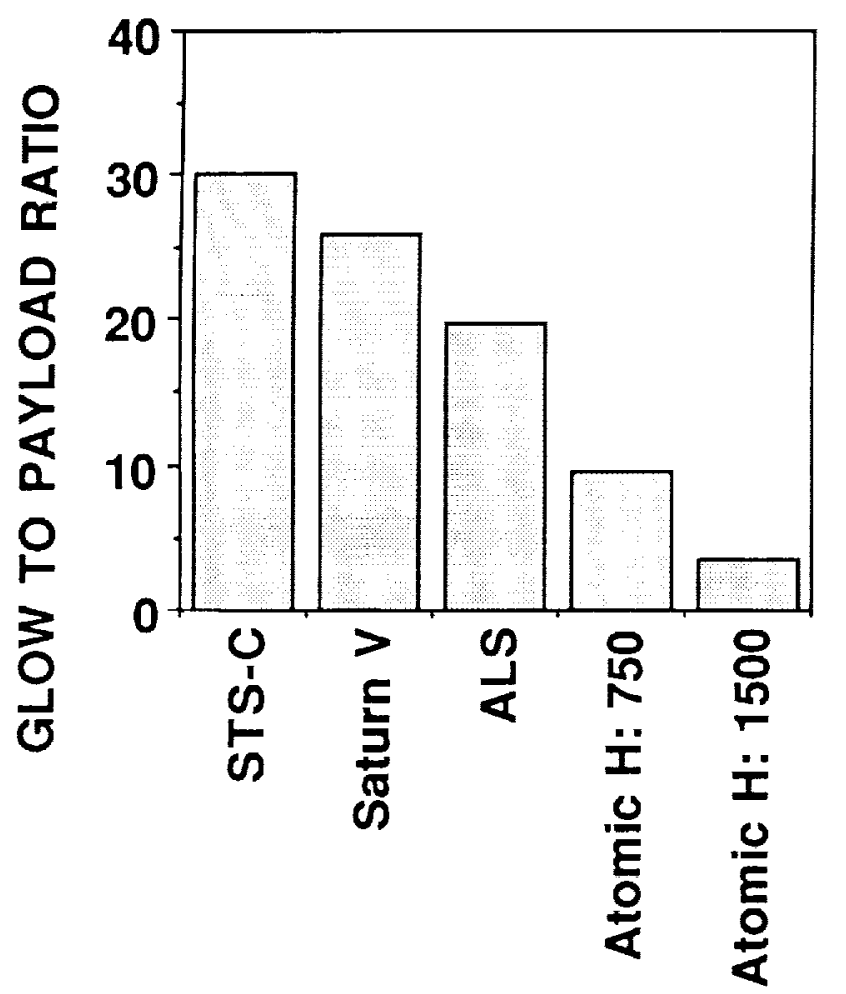

\section{PROPULSION TECHNOLOGY}

\author{
Figure 1. GLow to Payload Ratio \\ for Launch Vehicles
}

\section{Advanced Launch Vehicle Propulsion}

The current designs for the ALS and the Shuttle-c incorporate new technologies in the engines, propellant storage and feed systems and the launch operations. These advanced technologies, however, provide a small performance increase over the current state of the art in launch vehicle propulsion. Figure 1 contrasts the ratio of the GLOW to the payload delivered to Low Earth orbit (LEO). A Shuttle-C ratio is 30. The STS-C payload mass $(68,000 \mathrm{~kg})$ does not include the cargo element (the payload carrier and boattail with space shuttle Main Engines). The ALS has an improved performance over the Saturn V (Ref. 6); a ratio of 20 and 26 , respectively. An atomic hydrogen launch vehicle at an $I_{s p}$ of 750 and $15001 b_{f}-s / 1 b_{m}$ is also shown. With atomic hydrogen, the ratio of GLOW to LEO payload is reduced to 9.5 and 3.4 . This is 48 to 17 percent of that required by the state of the art ALS vehicles. By using a propellant such as atomic hydrogen, the mass of the launch vehicle can be reduced. These reductions in launch vehicle mass can be translated into smaller launch facilities, easier operations with the smaller launch vehicle stages and components and potentially lower overall costs for the advanced atomic hydrogen vehicle.

The comparison in Figure 1 is affected by several factors. For example, the saturn $V$ was a three stage vehicle delivering 113.4 metric tons to LEO. The STS-C delivers 68 metric tons to LEO and only has two stages. The ALS and the atomic hydrogen vehicles all deliver 96 metric tons. These comparisons are used only to contrast the overall performance of various launch systems.

In the analyses presented in the succeeding sections, several figures of merit will be used to compare the upper stages and the launch vehicles. Each vehicle has a different set of constraints and therefore a different measure of performance. For the upper stages, the figure of merit will be the injected mass (or payload) delivered to a injection energy. For the launch vehicles the GLOW will be the figure of merit.

\section{Atomic Hydrogen Propellants}

Atomic hydrogen is a free-radical propellant (Ref. 7). A very high energy can be released upon recombination of the hydrogen atoms. The theoretical energy release is 52.2 $\mathrm{kcal} / \mathrm{g}$. For a rocket propulsion system, this energy density implies an $I_{s p}$ of $1900 \quad \mathrm{lb}_{\mathrm{f}}$ $s / 1 b_{m}$. Past studies have considered atomic hydrogen as a propellant for very high $I_{\mathrm{sp}}$ propulsion systems (Refs. 7, 8 and 9). These studies used atomic hydrogen for upper stages of launch vehicles.

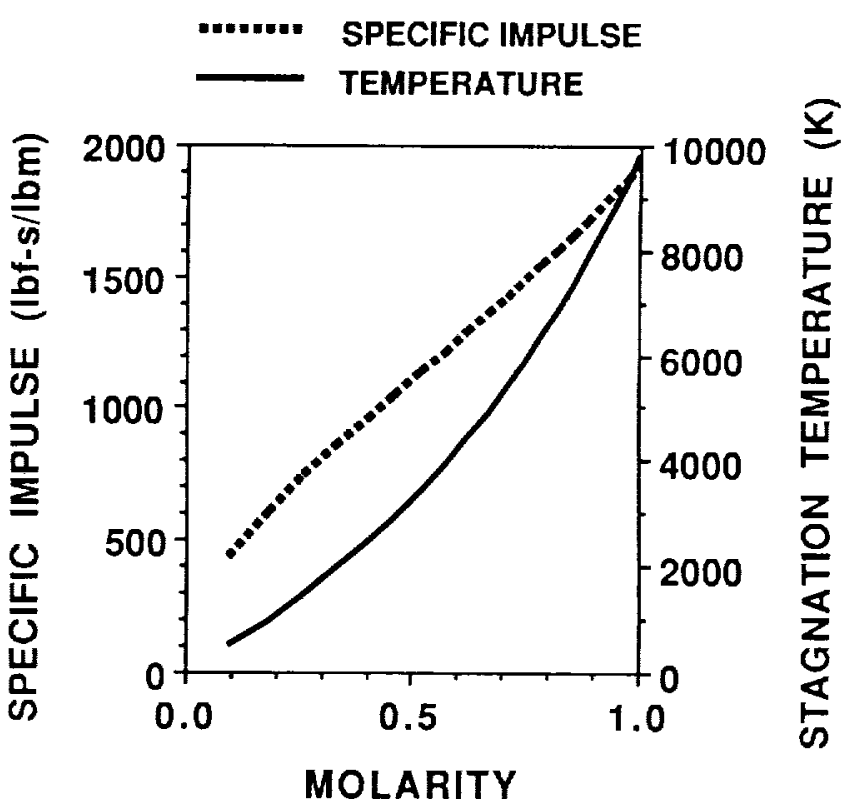

Figure 2. Atomic Hydrogen Specific Impulse

\section{Propulsion Performance and Specific Impulse}

Figure 2 depicts the $I_{s p}$ of this propellant. The corresponding stagnation temperature is also provided. The $I_{s p}$ is presented as a function of the molarity of the atomic hydrogen. At a $750-1 b_{f}-s / 1 b_{m} I_{s p}$, the reaction temperature is $1,500 \mathrm{~K}$. At an Isp of 1,500 $1 b_{f}-s / 1 b_{m}$, the stagnation temperature reaches $6000 \mathrm{~K}$. These two $I_{s p}$ s were used as examples of the propellant performance. 
The $I_{s p}$ in Figure 2 is shown as a function of the molarity of the atomic hydrogen. The molarity is:

$M=$ moles $\mathrm{H} /$ (moles $\mathrm{H}+$ moles $\mathrm{H}_{2}$ )

where:

M Molarity

The molecular weights of $\mathrm{H}_{2}$ and atomic hydrogen are $2.0158 \mathrm{~g} / \mathrm{mole}$ and 1.0079 $\mathrm{g} / \mathrm{mole}$, respectively. For a molarity of 0.266 , the weight fraction of atomic hydrogen would be 0.154 or 15.4 percent atomic hydrogen in the $\mathrm{H}_{2}$ matrix. To produce a $1500-1 b_{f}-s / 1 b_{m} I_{s p}$ the molarity must be 0.761 or a weight fraction of 61.5 percent atomic hydrogen in the solid $\mathrm{H}_{2}$ matrix.

The Isp is estimated using (Ref. 10)

$I_{s p}=265\left(m_{\mathrm{H}} Q\right)^{0.5}$

where:

$I_{s p} \quad$ Specific Impulse $\left(1 b_{f}-s / 1 b_{m}\right)$

$m_{B} \quad$ mass fraction of atomic hydrogen

Q Energy Release (52.2 $\mathrm{kcal} / \mathrm{g})$

The stagnation temperature is calculated using (Ref. 9):

$\mathrm{T}_{0}=\mathrm{MW}\left(\mathrm{I}_{\mathrm{sp}} * 27.4\right)^{2}$

where:

$\mathrm{T}_{0} \quad$ Stagnation Temperature

(K)

MW Exhaust Molecular Weight

\section{Volume-Constrained Upper Stages}

As part of the space Transportation system (STS), a high-energy upper stage is required for placing payloads into high earth orbits and onto planetary trajectories. Because the Centaur is unavailable as an option for planetary missions, the Inertial Upper stage (IUS) has been used as the primary STS upper stage. For a short trip time, many planetary missions require a high injection energy $\left(C_{3}\right)$. Atomic hydrogen has been studied for use in a launch vehicle upper stage (Ref. 8). In this section, the performance of an atomic hydrogen upper stage will be discussed for the STS-C.

Mission Analysis. The figure of merit for comparing upper stages is the injected mass. This is the total mass delivered to a specific $C_{3}$. The $C_{3}$ is defined as:

$c_{3}=\left(\left[\mu / r_{0}\right]^{0.5}+\Delta V\right)^{2}-2 \mu / r_{0}$

where:

$c_{3}$ Injection Energy $\left(\mathrm{km}^{2} / \mathrm{s}^{2}\right)$

$\Delta V$ Velocity Change $(\mathrm{km} / \mathrm{s})$ $\left(398601.3 \mathrm{~km}^{3} / \mathrm{s}^{2}\right)$

$r_{0} \quad$ Orbital Radius (km) or $6378.14 \mathrm{~km}$ + Orbital Altitude $(\mathrm{km})$

The orbital altitude for the upper stages described in this paper was $241 \mathrm{~km}(130$ nautical miles).

Upper Stage Figures of Merit. High performance for an upper stage can be defined in two ways: increased injected mass or increased $C_{3}$. Increasing the injected mass allows the upper stage to deliver added payload to its target. By increasing the $C_{3}$, the upper stage can provide a faster trip to the planets. Both of these benefits, higher injected mass and higher $c_{3}$, must be traded for each mission. The Galileo mission is a case in point. The original mission design included an injection toward Jupiter with a $\mathrm{C}_{3}$ of $79.2 \mathrm{~km}^{2} / \mathrm{s}^{2}$ using a centaur G-Prime (Ref. 11). The trip time to Jupiter was 1.5 years. With the IUS, the spacecraft was launched at a $c_{3}$ of $17 \mathrm{~km}^{2} / \mathrm{s}^{2}$ (Ref. 12). The trip time to Jupiter was extended to 6.5 years.

Upper stage Design Constraints. Using advanced propulsion for these upper stages can improve the performance of the sTs for many high energy missions. Table I provides the $I_{\mathrm{sp}} \mathrm{s}$ of the upper stages. Two high-I $I_{\mathrm{sp}}$ $\mathrm{O}_{2} / \mathrm{H}_{2}$ propulsion systems and two atomic hydrogen system were analyzed as possible IUS replacements. For the $\mathrm{O}_{2} / \mathrm{H}_{2}$ systems, an existing centaur G-Prime engine and an advanced engine were considered.

Table I

Propulsion system Specific Impulse

System $\quad I_{\mathrm{sp}}\left(1 b_{\mathrm{f}}-\mathrm{s} / 1 \mathrm{~b}_{\mathrm{m}}\right)$

$\begin{array}{ll}\mathrm{O}_{2} / \mathrm{H}_{2} \text { (Centaur Class) } & 446.4 \\ \text { Advanced } \mathrm{O}_{2} / \mathrm{H}_{2} \text { (STE) } & 480 \\ \text { Atomic Hydrogen } & 750,1500\end{array}$

An analysis was conducted for an atomic hydrogen vehicle constrained to the volume of the Centaur G-Prime in the STS cargo bay (Ref. 8). The performance of this vehicle for planetary missions was poor when compared to the then-currently baselined oxygen/hydrogen $\left(\mathrm{O}_{2} / \mathrm{H}_{2}\right)$ STS-Centaur G-Prime upper stage (Ref. 8). Though the $I_{s p}$ of the atomic hydrogen stage was higher than the Centaur, the total mass of propellant that could be carried in the STS bay was limited. The cases of a volume-limited and a masslimited atomic hydrogen upper stage were considered. The total propellant loads in the two types of stages were $5500 \mathrm{~kg}$ and $7973 \mathrm{~kg}$, respectively (Ref. 8). The $\mathrm{I}_{\mathrm{sp}}$ of both upper stages was $7401 b_{f}-s / 1 b_{m}$.

The volume limitation imposed by the STS and the centaur volume placed very severe constraints on the atomic hydrogen upper stage design. No performance advantage was 
gained using atomic hydrogen in this configuration. Also, the mass of the thermal control system and the magnetic field generator for the propellant storage system was carried in the orbiter bay. Their total mass was considered comparable to the Airborne support Equipment (ASE) for the centaur. The mass of this added ASE also reduced the mass available for the atomic hydrogen stage.

If the volume of the upper stage were not restricted to the fixed volume of the STS cargo bay, the performance of that vehicle would be enhanced. In this paper, an atomic hydrogen stage was designed to conform to the volume and mass constraints of the STS$C$ payload element (Ref. 4). The STS-C has a substantially longer cargo bay and can alleviate some of the volume constraints of the current space shuttle.

Though the $\mathrm{O}_{2} / \mathrm{H}_{2}$ stages can use the maximum STS-C payload mass capability, the volume of the payload element restricts the atomic hydrogen stage's tank length (and thus the total mass of propellant) that can be accommodated by the STS-C. Thus, the $\mathrm{O}_{2} / \mathrm{H}_{2}$ stages in the STS-C were mass limited. The stages using atomic hydrogen were volume limited. The total launch masses for the atomic hydrogen stages were significantly lower than the $68,000-\mathrm{kg}$ payload of the STSc.

In the performance calculations, the $\mathrm{O}_{2} / \mathrm{H}_{2}$ stages were sized for a maximal propellant load. This design point corresponds to an injected mass of $100 \mathrm{~kg}$. At all higher injected masses, the $\mathrm{O}_{2} / \mathrm{H}_{2}$ stage must have propellant offloaded from the tanks. With the atomic hydrogen stage, the stage's propellant density is sufficiently low that the stage is fully loaded with propellant for the full range of the injected masses.

In this analysis, the maximum total mass delivered to LEO (the stage, propellant, payload, adapter and ASE) was $68,000 \mathrm{~kg}$ (Ref. 4). The ASE mass was $4109 \mathrm{~kg}$ (Ref. 13). The total dry mass was fixed and propellant mass for the upper stages was allowed to vary over the range of injected masses. The propulsion mass-scaling equation for the stage was:

$m_{d r y}=1211.66+0.3160 m_{p}(k g)$

where:

$\begin{array}{ll}m_{d r y} & \text { Stage Burnout Mass }(\mathrm{kg}) \\ m_{p} & \text { Propellant Mass }(\mathrm{kg})\end{array}$

The propellant tank was 4 meters in diameter and 18.7 meters long. This tank length is accommodated by the 25-meter long STS-C payload element cargo bay (Ref. 4). This tank also holds the maximal propellant load for the atomic hydrogen upper stage: 18,300 $\mathrm{kg}$. This propellant mass was selected based on the volume and length constraint of the cargo bay. The remainder of the bay length accommodates the payload; this length is 6.3 meters ( 20 feet).

Two types of cryogenic stages were considered. An oxygen/hydrogen upper stage using an engine performance that is similar to the engines of the Centaur G-Prime was the first type of vehicle $\left(I_{s p}=446.4 \quad \mathrm{lb}_{\mathrm{f}}-\right.$ $\left.s / 1 b_{m}\right)$. A high-performance upper stage using a Space Transfer Engine (STE, Ref. 14) was also analyzed. The $I_{s p}$ of this vehicle was $4801 b_{f}-s / 1 b_{m}$. The propulsion mass-scaling equation for both types of stages was:

$m_{d r y}=350.55+0.1598 m_{p}(k g)$

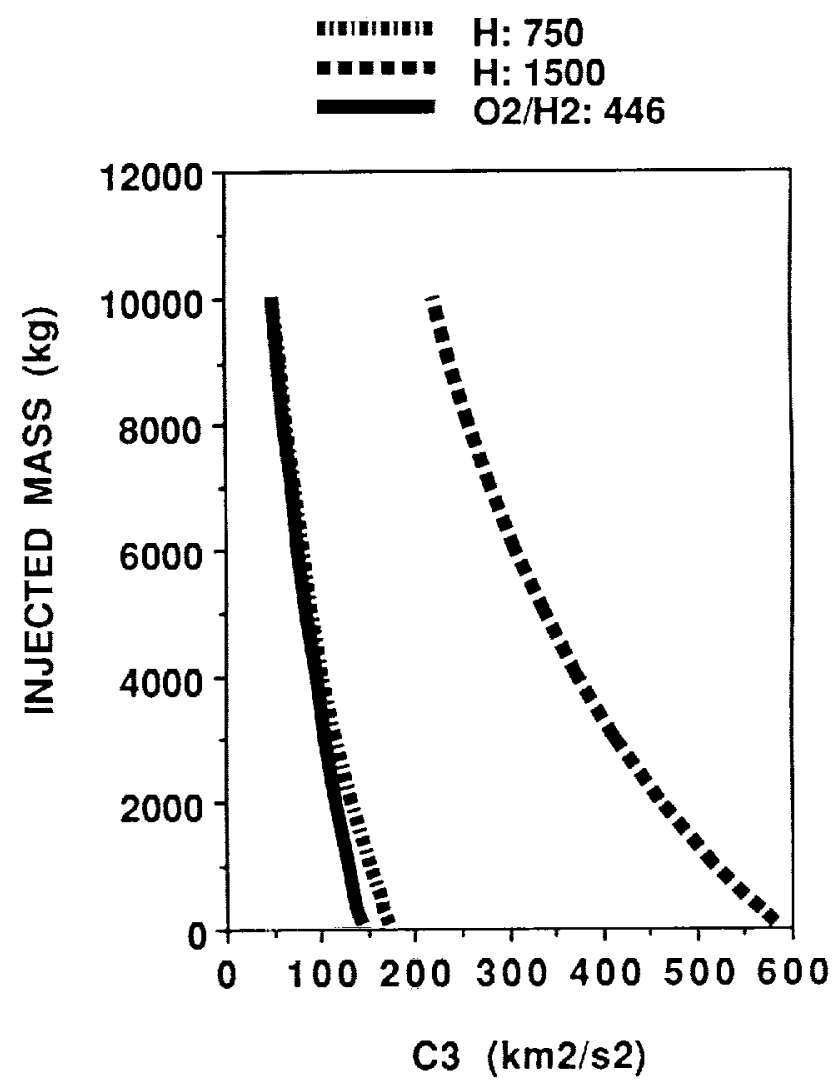

Figure 3. Upper Stage Performance: $\mathrm{O}_{2} / \mathrm{H}_{2}$ Stage $\left(446.4 \quad 1 \mathrm{~b}_{\mathrm{f}}-\mathrm{s} / 1 \mathrm{~b}_{\mathrm{m}} \mathrm{I}_{\mathrm{sp}}\right)$ and Atomic $\mathrm{H}$

Upper Stage Results. Figure 3 compares the injected mass capability for two atomic hydrogen upper stages with a stage that has the $I_{s p}$ of the centaur G-Prime. Because the $\mathrm{O}_{2} / \mathrm{H}_{2}$ stage was designed for the STS-C cargo bay, it has a substantially higher propellant load: up to $54,700 \mathrm{~kg}$ rather than $20,300 \mathrm{~kg}$ for the centaur. The $C_{3}$ ranges from 0 to $600 \mathrm{~km}^{2} / \mathrm{s}^{2}$. A $C_{3}$ of 10 to $86 \mathrm{~km}^{2} / \mathrm{s}^{2}$ is representative of that required for many past, currently-planned and future planetary missions (Refs. 11, 12 and 13).

Using atomic hydrogen at an $I_{s p}$ of $750 \quad 1 b^{-}$ $s / 1 b_{m}$ provides only a small performance benefit. It provides a benefit for missions requiring a $C_{3}$ greater than $50 \mathrm{~km}^{2} / \mathrm{s}^{2}$. It can 
deliver $6200 \mathrm{~kg}$ to a $C_{3}$ of $80 \mathrm{~km}^{2} / \mathrm{s}^{2}$ while the $\mathrm{O}_{2} / \mathrm{H}_{2}$ stage can deliver over $5700 \mathrm{~kg}$. This $C_{3}$ is representative of an outer planet mission on a direct injection (no Earth or Venus Gravity Assist maneuvers required). only when operating the system at a 1500$1 b_{f}-s / 1 b_{m} I_{s p}$ does atomic hydrogen provide a significant performance advantage over the $\mathrm{O}_{2} / \mathrm{H}_{2}$ stage. At a $\mathrm{C}_{3}$ of $80 \mathrm{~km}^{2} / \mathrm{s}^{2}$, the atomic hydrogen upper stage $\left(I_{s p}=15001 b_{f}-s / 1 b_{m}\right)$ is able to inject over $26,500 \mathrm{~kg}$.

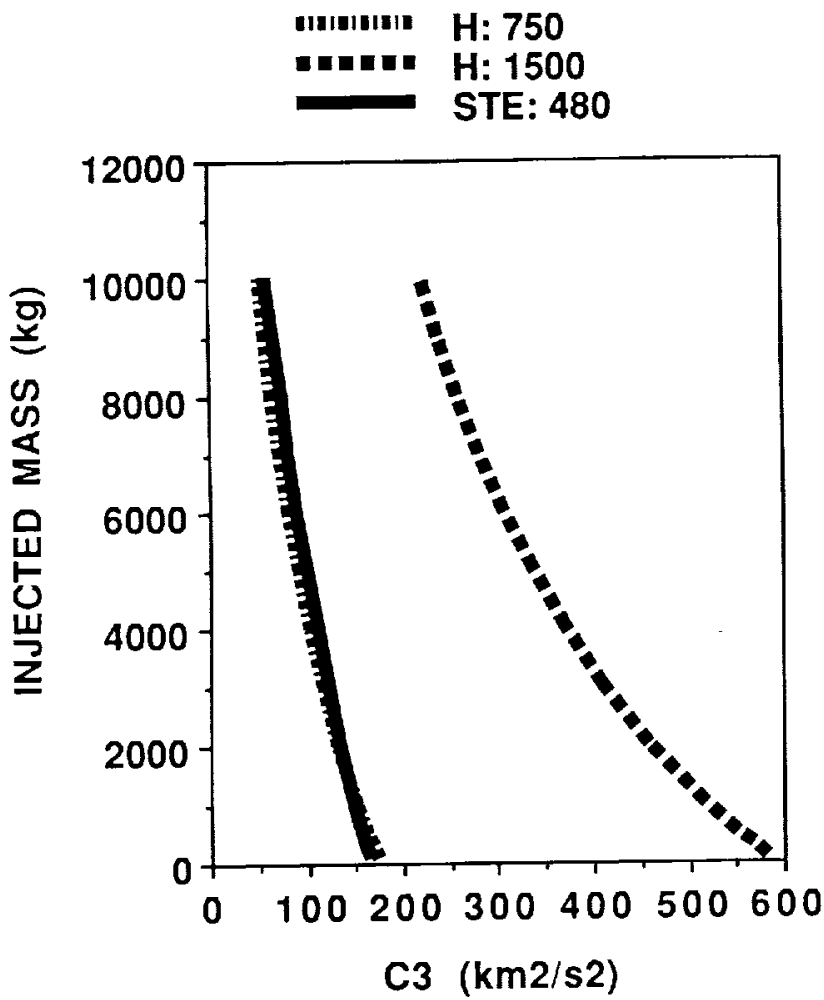

Figure 4. Upper Stage Performance: STE Stage and Atomic $\mathrm{H}$

Figure 4 provides the performance comparison of the STE-based stage with atomic hydrogen. In sizing the STE stage, the full $68,000-\mathrm{kg}$ payload capability of the STS-C was assumed. To fit within the volume and mass limitations of the STS $-C$, the hydrogen tank diameter was 4.5 meters and the oxygen tank diameter was 3.05 meters. The maximal propellant mass for the stage is the same as that with the lower $I_{\mathrm{sp}}$ stage: $54,700 \mathrm{~kg}$.

The STE stage provides a similar performance to the atomic hydrogen upper stage (with a $\left.750-1 b_{f}-s / 1 b_{m} I_{s p}\right)$. For near-term upper stage applications, an advanced $\mathrm{O}_{2} / \mathrm{H}_{2}$ upper stage would provide the potential performance of atomic hydrogen. As with the previous analysis, only when the atomic hydrogen $I_{s p}$ is greater than $7501 b_{f}-s / 1 b_{m}$ will it provide a benefit over advanced $\mathrm{O}_{2} / \mathrm{H}_{2}$ propulsion.

This STE stage does provide a large payload benefit over the $\mathrm{O}_{2} / \mathrm{H}_{2}$ stage presented in Figure 3. At a $C_{3}$ of $80 \mathrm{~km}^{2} / \mathrm{s}^{2}$, the injected mass is $7,300 \mathrm{~kg}$. This is $1,600 \mathrm{~kg}$ more than the stage with a $446.4-1 b_{f}-s / 1 b_{m} I_{s p}$.

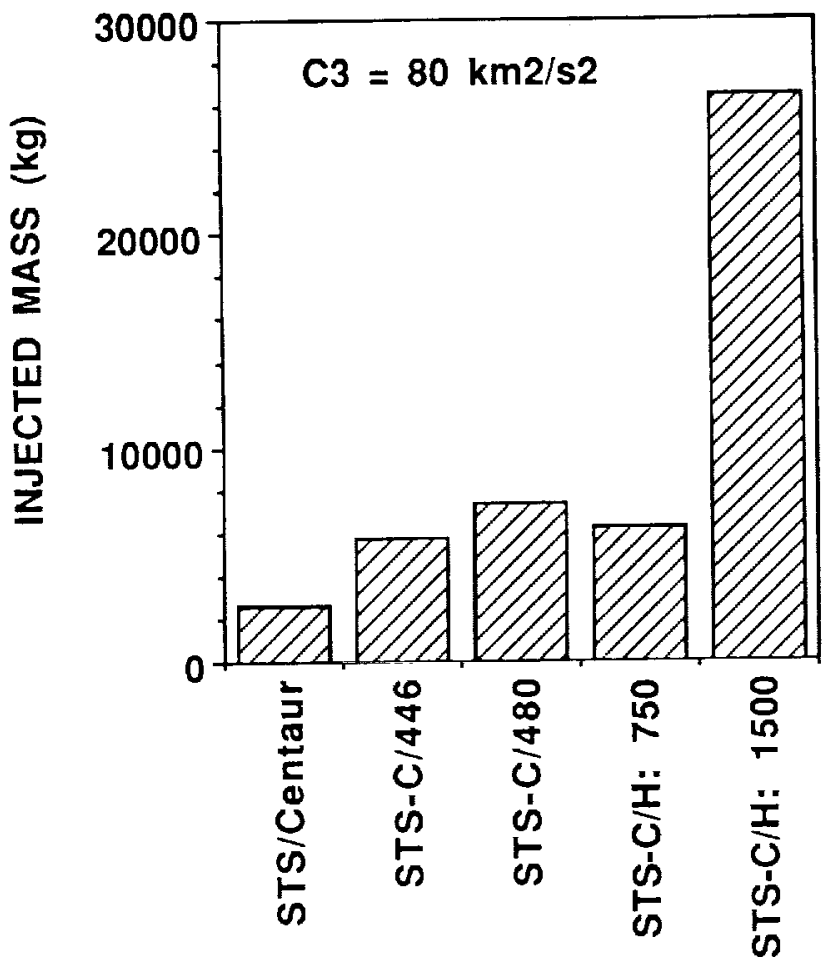

UPPER STAGE TECHNOLOGY

Figure 5. Upper Staqe Injected Mass:
\[ C_{3}=80 \mathrm{~km}^{2} / \mathrm{s}^{2} \]

oxygen/Hydrogen Propulsion Benefits, It should be noted that the centaur G-Prime that was planned for the current STS had significantly lower performance than either of the $\mathrm{O}_{2} / \mathrm{H}_{2}$ stages discussed above. Figure 5 compares the systems discussed above: the three $\mathrm{O}_{2} / \mathrm{H}_{2}$ options and the two atomic hydrogen stages. The injected masses for the cryogenic stages in the STS-C were more than doubled over the centaur. Aboard the current STS, the centaur G-Prime was only able to inject $2600 \mathrm{~kg}$ to a $\mathrm{C}_{3}$ of $80 \mathrm{~km}^{2} / \mathrm{s}^{2}$. Thus, the STS-C with an improved large cryogenic stage can provide a considerable benefit to the planetary program.

Upper Stage Observations. Future atomic hydrogen propellants may provide an important performance advantage over chemical propulsion upper stages. This high performance for an upper stage is only attainable for high densities of atomic hydrogen. The high performance level of 1500 $1 b_{f}-s / 1 b_{m}$ should only be considered for farterm missions. An extensive program of basic research and development is needed to determine whether such densities are feasible and producible.

\section{Launch Vehicle Performance Analysis}

The significant performance penalties associated with a volume-constrained upper stage will be relaxed in the design of a launch vehicle. The major volume constraints in a launch vehicle are determined by the ability to easily manufacture its elements 
and to transport them to and about the launch site. Its volume is much less constrained than an upper stage in the STS or STS-C cargo bay. Also, the mass and volume associated with the refrigeration facility and the magnetic field coils for storing atomic hydrogen can be left at the launch site. By placing the mass of these facilities on the ground, the launch vehicle will no longer be constrained to "pay" the mass and volume penalties associated with the STS.

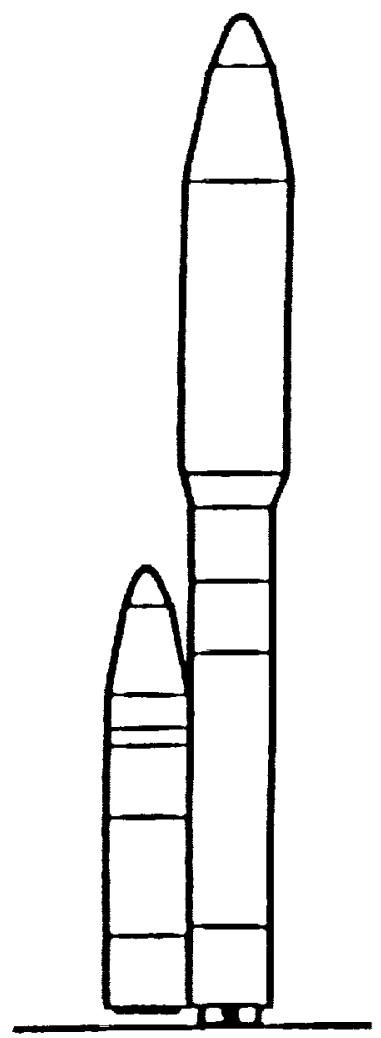

Figure 6. ALS Configuration Using $\mathrm{O}_{2} / \mathrm{H}_{2}$

Current ALS Vehicle Designs. Figure 6 depicts a possible configuration for the ALS. Many different design concepts are being investigated. In this analysis, two different payloads to Low Earth orbit (LEO), each with a different propellant combination was considered.

One design used an $\mathrm{O}_{2} / \mathrm{H}_{2} / \mathrm{RP}-1$ booster with an $\mathrm{O}_{2} / \mathrm{H}_{2}$ main core section. Hydrogen from the core was used in the booster propulsion system. The booster $I_{s p}$ was $356.61 b_{f}-s / 1 b_{m}$ (vacuum performance). Each of the five engines delivered a thrust of $676,7701 \mathrm{~b}_{\mathrm{f}}$.

A module on the booster and the core containing the propulsion system and avionics was recovered and reused. In the core section, three space shuttle Main Engines provided an $I_{\mathrm{sp}}$ of $452.91 \mathrm{~b}_{\mathrm{f}}-\mathrm{s} / 1 \mathrm{~b}_{\mathrm{m}}$. Each had a thrust of $470,000 \quad 1 b_{f}$. The payload delivered to orbit was $43,000 \mathrm{~kg}$. It had a GLOW of $1,192,000 \mathrm{~kg}$. In the second design, the vehicle used $\mathrm{O}_{2} / \mathrm{H}_{2}$ in the core and boosters. Its payload to orbit was $96,000 \mathrm{~kg}$ and its GLOW was $1,891,000 \mathrm{~kg}$.

Atomic Hydrogen Mission Analysis. The atomic hydrogen launch vehicle design used two stages. Each stage delivered one half of the total $9.7-\mathrm{km} / \mathrm{s} \Delta \mathrm{V}$. This $\Delta \mathrm{V}$ included 9.2 $\mathrm{km} / \mathrm{s}$ (Refs. 15 and 16) for the primary ascent to orbit and the typical gravity losses and a $0.5 \mathrm{~km} / \mathrm{s} \Delta V$ for other additional gravity losses (drag due to differing configurations and very high accelerations) of the launch vehicle. The second stage also delivered an additional 50 $\mathrm{m} / \mathrm{s}$ after it burned out for a payload separation maneuver.

Propulsion System Mass Scaling. For the launch vehicle, the atomic hydrogen was stored in a solid $\mathrm{H}_{2}$ matrix. This matrix was stored at $4 \mathrm{~K}$. Its density was $88 \mathrm{~kg} / \mathrm{m}^{3}$ (Ref. 17). The propellant tank operating pressure was 30 psia and the maximum expected operating pressure was 50 psia. A 6.1-meter diameter tank was used and the feed system was pressure-fed. The propellant residual and holdup mass was 1.5 percent of the total propellant mass. An ullage volume of 6 percent was used. The engine for each stage had a 60:1 expansion ratio nozzle. The chamber pressure for this engine was 30 psia. The propulsion mass-scaling equation for the stage was:

$m_{d x y}=10940+0.2883 m_{p}(k g)$

Table II

Atomic Hydrogen Launch Vehicle Mass Summary $I_{s p}=7501 b_{f}-s / 1 b_{m}$

Element

Mass (kg)

Payload

95,708

Fairing

7,648

Payload Adapter

5,440

Stage 2:

Tankage

Thermal Control

15,039

Engine and

Feed System 10,000

structure

Residuals and Holdup

10,777

2,345

Contingency

5,030

Propellant

153,963

Interstage Adapter

16,741

Stage 1:

Tankage

Thermal control

43,436

Engine and

Feed System

34,576

structure

Residuals and Holdup

10,000

30,901

6,722

12,563

Propellant

441,438

Total 
Also included in the launch vehicle massscaling equation was the thermal control system with insulation and a Thermodynamic vent System/Vapor-Cooled Shield (TVS/VCS), the structure and the propeliant feed system. Table II provides a mass summary for the two-stage vehicle.

As an added mass apart from the propulsion mass-scaling equation, a $7648-\mathrm{kg}$ payload fairing or shroud was also provided on the launch vehicle. It was carried all the way to orbit.

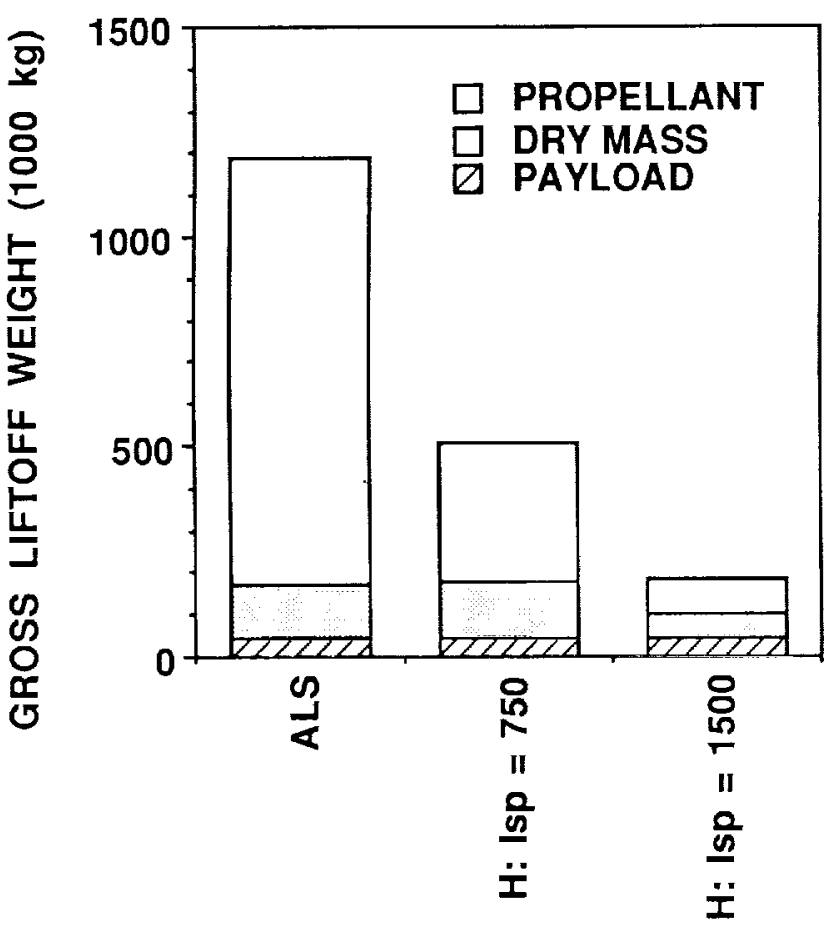

PROPULSION TECHNOLOGY

Figure 7. Launch Vehicle GLOW: 43,000-kg LEO Payload

Launch Vehicle Results, Figure 7 compares the ALS and the atomic hydrogen launch vehicles GLOW for the $43,000-\mathrm{kg}$ payload. Table III lists the GLOWs for both vehicle designs. The mass savings for the atomic hydrogen vehicle with an $I_{s p}$ of 750 $1 b_{f}-s / 1 b_{m}$ was 58 percent. An 85 -percent GLOW reduction was achieved with a $1500-1 b_{\mathrm{f}}-\mathrm{s} / 1 \mathrm{~b}_{\mathrm{m}}$ $I_{\text {sp }}$. In the same comparison for the $96,000-$ $\mathrm{kg}$ payload, the mass savings for the $750-$ $1 b_{f}-s / 1 b_{m} I_{s p}$ is over 52 percent. The GLOW reduction was 83 percent at an $I_{\text {sp }}$ of 1500 $1 b_{f}-s / 1 b_{m}$.

The analyses of both the upper stages' and the launch vehicles' performance shows that the highest benefit can be derived from atomic hydrogen in a launch vehicle. At a $750-1 b_{f}-s / 1 b_{m} I_{s p}$, the large GLOW reductions ( 52 to 58 percent) that are achieved can potentially reduce the cost of Earth to orbit operations. Additional performance increases to $1500 \quad 1 b_{f}-s / 1 b_{m}$ can further
Table III

Launch Vehicle GLOW Comparison

system GLOW ( $\mathrm{kg}$ )

Payload: $43,000 \mathrm{~kg}$

\begin{tabular}{lrr} 
ALS & \multicolumn{1}{r}{$1,191,900$} \\
Atomic Hydrogen: 750 & 504,095 \\
1500 & 183,267 \\
& \multicolumn{3}{c}{} \\
Payload: $96,000 \mathrm{~kg}$ \\
ALS \\
Atomic Hydrogen: 750 & $1,891,500$ \\
1500 & 914,461 \\
& & 326,879
\end{tabular}

reduce the GLOW by 82 to 85 percent over the ALS GLOW.

Engine and Nozzle Design. The performance levels for the atomic hydrogen vehicle are based on an engine with a 30-psia chamber pressure. This low pressure for a launch vehicle requires a large nozzle. A $10,000-\mathrm{kg}$ mass was allocated for the engine on each stage. This estimate will be refined as more detailed designs for the engine system are developed.

For the $750-1 b_{f}-s / 1 b_{m} \quad I_{s p}$ vehicle, the stagnation temperature of the atomic hydrogen recombination is 1500 to $2000 \mathrm{~K}$. This relatively low temperature is comparable to the current state of the art propulsion engine temperatures. At the high temperature predicted for the higher 1500$1 b_{f}-s / 1 b_{m} I_{s p}$, the stagnation temperature is $6000 \mathrm{~K}$. This high temperature and $I_{\mathrm{sp}}$ nozzle may require a combination of regenerative and transpiration cooling. Additional performance analyses are planned to determine the effect of chamber pressure and temperature on the engine design.

Launch Vehicle Thrust Level. An engine thrust level for the first and second stages of the launch vehicles are 1 isted in Table IV. The burn rate for the $750-1 b_{\varepsilon}-s / 1 b_{m} I_{s p}$ launch vehicle design $(96,000-\mathrm{kg}$ payload) is $1340 \mathrm{~kg} / \mathrm{s}$. This rate was computed using an initial thrust to weight $(T / W)$ for the vehicle at liftoff of 1.1. At an $I_{s p}$ of 1500 $1 b_{\mathrm{f}}-\mathrm{s} / 1 \mathrm{~b}_{\mathrm{m}}$, the mass flow is $240 \mathrm{~kg} / \mathrm{s}$.

In applying atomic hydrogen to propulsion, the very fast recombination rate must be considered. A recombination rate of $210 \mathrm{~cm} / \mathrm{s}$ is predicted for atomic hydrogen (Ref. 10). This rate is analogous to (and substantialiy higher than) the burn rate of solid propellants. A typical solid burn rate for STS-C is $0.947 \mathrm{~cm} / \mathrm{s}(0.373 \mathrm{in} / \mathrm{s}$, Ref. 4). This high recombination rate can produce very high accelerations for the launch vehicle.

To control the vehicle thrust level, the propellant can be segmented. The segmenting will prevent the neighboring propellant from recombining (Ref. 8). One possible design would introduce a "pelletized" propellant 
Table IV

Atomic Hydrogen

Launch Vehicle Thrust Levels

system

Thrust Level $\left(1 b_{f}\right)$

Payload: $43,000 \mathrm{~kg}$

$\begin{array}{lr}7501 b_{\mathrm{f}}-\mathrm{s} / 1 \mathrm{~b}_{\mathrm{m}} & 1,222,000 \\ \text { Stage } 1 & 414,000 \\ \text { Stage } 2 & \\ & \\ 15001 \mathrm{~b}_{\mathrm{f}}-\mathrm{s} / 1 \mathrm{~b}_{\mathrm{m}} & 445,000 \\ \text { Stage } 1 & 244,000 \\ \text { Stage } 2 & \end{array}$

Payload: 96,000 kg

$\begin{array}{lr}7501 b_{f}-s / 1 b_{\text {rb }} & \\ \text { Stage } 1 & 2,218,000 \\ \text { Stage } 2 & 771,000 \\ 15001 b_{f}-s / 1 b_{m} & \\ \text { Stage } 1 & 793,000 \\ \text { Stage } 2 & 456,000\end{array}$

Initial Thrust to Weight $=1.1$

into the "combustion" or recombination chamber. The rate of recombination of the total propellant load can therefore be controlled and control of the vehicle thrust level is more easily achieved.

In Ref. 8, an insulator was used to isolate the individual atomic hydrogen propellant elements from each other. The materials selected were hafnium dioxide and zirconium dioxide. This insulator was selected for its thermal properties and its ability to maintain the temperature of the propellant element below $1 \mathrm{k}$ for a short duration. A derivative of this type of approach may be used to inhibit the propellant recombination.

The launch vehicle will require very large propellant elements. If the propellant burn rate is $1340 \mathrm{~kg} / \mathrm{s}$, and if one element is burned per second, the number of elements required will be:

\section{$441,440 \mathrm{~kg}$ of propellant $1340 \mathrm{~kg}$ per element \\ $=330$ elements}

for the first stage of the $750-1 b_{f}-s / 1 b_{m} I_{s p}$ vehicle $(96,000-\mathrm{kg}$ payload). This type of segmenting, however, may ease the propellant production, transportation and operations. If the propellant is fabricated in smaller elements, the size and cost of the production facility may be reduced. A large facility to produce atomic hydrogen in the $100,000-\mathrm{kg}$ propellant tanks would no doubt be more massive than one with the requirement to produce smaller elements with an individual mass of $1000 \mathrm{~kg}$.
System-Level Design Issues

To deliver the propulsion performance discussed above, several challenging technologies will have to be developed. The production, transportation and long-term storage of large quantities of atomic hydrogen will be needed. Each of these areas and their effect on the launch vehicle processing is discussed below.

\section{Production and storage Methods}

Currently, no methods of producing or storing large amounts of atomic hydrogen exist. A series of preliminary studies and experiments on the production methods were conducted from the 1950's through the 1980's (Refs. 7, 9, 10, 18 and 19). These past research programs estimated the storage density of atomic hydrogen and proposed storage methods using solid or gaseous $\mathrm{H}_{2}$ as a storage matrix.

There are two storage methods for atomic hydrogen. One uses a solid hydrogen matrix (Refs. 10, 18 and 19). Atomic hydrogen is formed in the solid hydrogen. The second method is called Bose-Einstein Condensation (BEC, Ref. 20).

In the first method, the atomic hydrogen will be placed in the hydrogen matrix by one of several methods: electron beams, radiofrequency discharge and radioactive decay of tritium (Ref. 21). Current experiments (Ref. 21) are using tritium decay for the atomic hydrogen production. The specific method used for producing large quantities will depend on the cost and the ease of process control.

The highest storage density for atomic hydrogen has been achieved in a solid hydrogen matrix (Ref. 21). This matrix is a solid at a temperature of 4 to $16 \mathrm{~K}$. The achieved density is 0.5 to 1 percent of atomic hydrogen (by weight) in the solid hydrogen. As discussed above, this storage density is substantially lower than that required for launch vehicle propulsion. Future experiments will determine if there is a mechanism for increasing this density to the needed levels.

with the second method, Bose-Einstein Condensation, the storage density that results is very low. This is because the atomic hydrogen is formed gaseous matrix and then cooled (Ref. 20). The density of atomic hydrogen that is produced with this method can be several orders of magnitude lower than using a solid hydrogen matrix. Because of the low storage density produced, it has been rejected as a useful method for storing atomic hydrogen for propulsion.

\section{Kapitza Effect and Low Temperatures}

storing the atomic hydrogen at temperatures lower than $4 \mathrm{~K}$ has been considered (Refs. 10, 19 and 20). These lower temperature have 
the potential for increasing the storage time (time without recombination of the atomic hydrogen). A temperature of $4 \mathrm{~K}$ was chosen to avoid thermal problems associated with the Kapitza effect. This effect results in an increased thermal resistance at temperatures below $4 \mathrm{~K}$. At temperatures below $4 \mathrm{~K}$, the transmission of energy is not controlled by conduction but by an acoustic coupling (Ref. 22). As the temperature is reduced, the resistance increases. Attaining a very low temperature is therefore extremely difficult. Operating the storage facility at $4 \mathrm{~K}$ will obviate this problem.

\section{Long-Term storage and Transfer}

Magnetic Field strength. A high magnetic field has been proposed as a way of extending the storage time of atomic hydrogen (Refs. 10, 18 and 19). A 30kilogauss magnetic field was predicted for atomic hydrogen storage (Ref. 18). This magnetic field strength is a function of the storage time and the storage temperature. Research is continuing on the effect of the fields on inhibiting the recombination.

At the launch site, a very long storage time of months will be needed. The propellant will be in deep cryogenic storage. Because the propellant loads are large, the magnet and the refrigeration facilities will be substantial. The first and second stages of the $750-1 b_{f}-s / 1 b_{m} \quad I_{s p}$ vehicle require propellant loads of 441,440 and $154,000 \mathrm{~kg}$, respectively $(96,000-\mathrm{kg}$ payload).

An important point to consider is that the magnetic field coils do not have to be part of the launch vehicle. Atomic hydrogen does require the use of intense magnetic fields for long-term storage. To use atomic hydrogen for launch vehicle propulsion, the propellant must be prevented from recombining for the short period from launch to achieving orbit. Storage times of minutes to hours have been achleved (Ref. 18). For a launch vehicle, the total vehicle firing time is only 10 to 15 minutes. Thus, the predicted and demonstrated storage times are sufficient to allow the vehicle to reach orbit.

\footnotetext{
Propellant operations and Facilities. A 4-K temperature for the launch vehicle will require new facilities. This temperature will require large amounts of liquid helium at the launch site. It will be used for cooling the superconducting magnetic field coils and for producing and maintaining the solid hydrogen matrix.
}

Atomic hydrogen may have to be produced at the launch site. Transportation of the propellant from a remote site may require the movement of large magnetic bottles. The very high field strengths of the bottles would require large massive surface- or ship-based transporters. As discussed above, a production facility for small propellant "elements" may be an option. This facility may be small given the reduced size of the atomic hydrogen elements $(1000 \mathrm{~kg})$.
Transporting large numbers of smaller elements may be more cost effective than moving large single $100,000 \mathrm{~kg}$ propellant loads or elements.

\section{Conclusions}

Atomic hydrogen propulsion systems can potentially produce a very high $I_{s p}$. This high performance level can significantly reduce the launch mass of future launch vehicles. Using atomic hydrogen with an $I_{s p}$ of 750 and $15001 b_{\mathrm{f}}-\mathrm{s} / 1 \mathrm{~b}_{\mathrm{m}}$, very large GLOW reductions over the current aLs launch vehicle designs are possible.

Upper stages using atomic hydrogen can also be a benefit to the NASA planetary program and for orbital transfer. Only stages with an $I_{s p}$ significantly greater than $750 \quad 1_{f_{f}}$ $\mathrm{s} / 1 \mathrm{~b}_{\mathrm{m}}$, however, will provide a significant performance advantage of $\mathrm{O}_{2} / \mathrm{H}_{2}$ propulsion upper stages. Constraining the stage to the volume of the STS-C cargo bay restricts the atomic hydrogen stage performance at the lower $I_{\mathrm{sp}} \mathbf{s}$.

This free-radical propellant brings with it a set of unique challenges for the rocket propulsion designer. Producing and storing atomic hydrogen for propulsion will require both low cryogenic temperatures (near $4 \mathrm{~K}$ ) and high magnetic fields (as high as 30 kilogauss or 3 Tesla). Large magnet and refrigeration facilities to produce and store the propellant will be needed. To produce the atomic hydrogen either tritium decay, radiofrequency excitation or electron beams will be needed.

A significant amount of systems design will be required to determine the final "best" design for the atomic hydrogen launch vehicle and its support facilities. Additional analyses of these systems will provide insight into the complexity of transporting and storing atomic hydrogen in a realistic, operational environment.

clearly, a considerable amount of both basic technology and basic physics research is required before the possible benefits of atomic hydrogen can be fully determined. There may be significant benefit for a launch vehicle or an upper stage, but the potential must be matched by demonstrations of high storage density and controllability as a rocket propellant.

\section{References}

1) Wormington, J., "Technical Baseline Document, Advanced Launch System (ALS)," United States Air Force Astronautics Laboratory, May 15, 1988.

2) Harsh, M., "Shuttle-C, Evolution to a Heavy Lift Launch "Vehicle," NASA Marshall space Flight center, AIAA Paper 89-2521, AIAA/ASME/SAE/ASEE 25th Joint Propulsion Conference, Monterey, CA, JulY 10-12, 1989. 
Burg, R., et al., "Shuttle-C Main Propulsion System Development from the Space Transportation System Shuttle," Rockwell International, AIAA Paper 892503, AIAA/ASME/SAE/ASEE 25th Joint Propulsion Conference, Monterey, CA, July 10-12, 1989.

4) Harsh, M., "Shuttle-C Design Data Book," NASA Marshall space Flight Center, November 22, 1988 (revised February 24, 1989).

5) Proceedings of the High Energy Density Matter Conference, Air Force Astronautics Laboratory Document AL-CP89-002, July 1989.

6) "Weight and Performance Summary - July 1966," Apollo Systems Engineering, National Aeronautics and Space Administration, Washington, DC, SE 015005-1A, NASA TM-X-61019, August 15, 1966 .

7) Bass, A. and Brodia, H. (editors), Formation and Trapping of Free Radicals, National Bureau of Standards, Academic Press, New York, 1960.

8) Frisbee, R., "Ultra High Performance Propulsion for Planetary spacecraft: FY'83 Final Report," Jet Propulsion Laboratory, JPL D-1194, December 1983.

9) Hawkins, C. E., et al., "Free Radical Propulsion Concept, " Northern Kentucky University, AIAA Paper 81-0676, presented at the AIAA/JSASS/DGLR 15th International Electric Propulsion Conference, Las Vegas, NV, April 21-23, 1981.

10) Rosen, G., "Manufacture and Deflagration of an Atomic Hydrogen Propellant," Drexel University, AIAA Journal, Volume 12 , Number 10 , pp. 1325-1330, October 1974 .

11) Nolan, B., "Galileo Performance Assessment Report," Jet Propulsion Laboratory, JPL Document 1625-253, D2177 , February 15, 1985.

12) Longuski, J., and Nolan, B., "Galileo Performance Assessment Report," Jet Propulsion Laboratory, JPL Document 1625-261, Rev. A, D-2379, October 1, 1987 .

13) Palaszewski, B., "Oxygen/Hydrogen Propulsion Module for Planetary Injection Energy Augmentation, " Jet Propulsion Laboratory, presented at the JANNAF Propulsion Meeting, San Diego, CA, April 9-12, 1985.
14) Hannum, N., et al., "NASA's Chemical Transfer Propulsion Program for Pathfinder," NASA Lewis Research Center, NASA Technical Memorandum 102298, AIAA Paper 89-2298, presented at the AIAA/ASME/SAE/ASEE 25th Joint Propulsion Conference, Monterey, CA, July 10-12, 1989.

15) Weldon, v., et al., "Booster/Propulsion Vehicle Impact study - Final Report," Boeing Aerospace Company, D180-30083, NASA Contract NAS8-36944, June 1988.

16) Johnson, P., et al., "Booster/Propulsion Vehicle Impact study - Final Report," Martin Marietta Corporation, MCR-88-1000, NASA Contract NAS8-36945, February 8, 1988.

17) Mccarty, R., et al., "Selected Properties of Hydrogen (Engineering Design Data), National Bureau of Standards Monograph 168 , February 1981.

18) Webeler, R., "Behavior of Atomic Hydrogen in Solid $\mathrm{H}_{2}$ From 0.2 to 0.8 $\mathrm{K}$," NASA Lewis Research Center, The Journal of Chemical Physics, Volume 64, Number 5, March 1, 1976.

19) Rosen, G., et al, "Are Large Concentrations of Atomic $\mathrm{H}$ Storable in Tritium-Impregnated Solid in $\mathrm{H} 2$ Below $0.10 \mathrm{~K}$ ?, "Drexel University, Lettere al Cimento, Volume 26, Series 2, December 22,1979 .

20) Hardy, w., et al., "Magnetic Resonance Studies of Gaseous Atomic Hydrogen confined at $1 \mathrm{~K}$ and Zero Magnetic Field, " University of British Columbia, Physical Review Letters, Volume 45, Number 6, August 11, 1980.

21) Gaines, J. R., "Energy storage in solid Molecular Hydrogen Due to Trapped Atoms," University of Hawail at Manoa, in Proceedings of the High Eneray Density Matter Conference, Air Force Astronautics Laboratory Document AL-CP89-002, July 1989.

22) Gray, K, (editor), "Non-Equilibrium Superconductivity, Phonons and Kapitza Boundaries" based on the proceedings of the NATO Advanced study Institute Meeting, Series B, Physics; Volume 65, Plenum Press, New York, 1981. 


\begin{tabular}{|c|c|c|c|}
\hline \multicolumn{4}{|c|}{ Report Documentation Page } \\
\hline 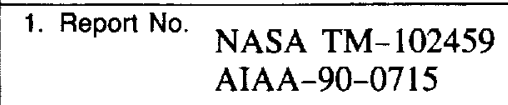 & 2. Government Accession No. & \multicolumn{2}{|c|}{ 3. Recipient's Catalog No. } \\
\hline \multirow{3}{*}{\multicolumn{2}{|c|}{$\begin{array}{l}\text { 4. Title and Subtitle } \\
\text { Atomic Hydrogen as a Launch Vehicle Propellant }\end{array}$}} & \multirow{2}{*}{\multicolumn{2}{|c|}{ 5. Report Date }} \\
\hline & & & \\
\hline & & \multicolumn{2}{|c|}{ 6. Performing Organization Code } \\
\hline \multirow{3}{*}{$\begin{array}{l}\text { 7. Author(s) } \\
\text { Bryan A. Palaszewski }\end{array}$} & & \multirow{2}{*}{\multicolumn{2}{|c|}{$\begin{array}{l}\text { 8. Performing Organization Report No. } \\
\text { E-5246 }\end{array}$}} \\
\hline & & & \\
\hline & & \multicolumn{2}{|l|}{$\begin{array}{l}\text { 10. Work Unit No. } \\
506-42\end{array}$} \\
\hline \multirow{2}{*}{\multicolumn{2}{|c|}{$\begin{array}{l}\text { 9. Performing Organization Name and Address } \\
\text { National Aeronautics and Space Administration } \\
\text { Lewis Research Center } \\
\text { Cleveland, Ohio 44135-3191 }\end{array}$}} & \multicolumn{2}{|c|}{ 11. Contract or Grant No. } \\
\hline & & \multirow{2}{*}{\multicolumn{2}{|c|}{$\begin{array}{l}\text { 13. Type of Report and Period Covered } \\
\text { Technical Memorandum }\end{array}$}} \\
\hline \multirow{2}{*}{\multicolumn{2}{|c|}{$\begin{array}{l}\text { 12. Sponsoring Agency Name and Address } \\
\text { National Aeronautics and Space Administration } \\
\text { Washington, D.C. 20546-0001 }\end{array}$}} & & \\
\hline & & \multicolumn{2}{|c|}{ 14. Sponsoring Agency Code } \\
\hline \multicolumn{4}{|c|}{$\begin{array}{l}\text { Prepared for the 28th Aerospace Sciences Meeting sponsored by the American Institute of Aeronautics and } \\
\text { Astronautics, Reno, Nevada, January } 8-11,1990 \text {. }\end{array}$} \\
\hline \multicolumn{4}{|c|}{$\begin{array}{l}\text { An analysis of several atomic hydrogen launch vehicles was conducted. A discussion of the facilities and the tech- } \\
\text { nologies that would be needed for these vehicles is also presented. The Gross Liftoff Weights (GLOW) for two } \\
\text { systems were estimated; their specific impulses }\left(\mathrm{I}_{\mathrm{sp}}\right) \text { were } 750 \text { and } 1500 \mathrm{lb}_{\mathrm{r}} \mathrm{s} / \mathrm{lb}_{\mathrm{m}} \text {. The atomic hydrogen launch } \\
\text { vehicles were also compared to the currently planned Advanced Launch System design concepts. Very significant } \\
\text { GLOW reductions of } 52 \text { to } 85 \text { percent are possible over the Advanced Launch System designs. Applying atomic } \\
\text { hydrogen propellants to upper stages was also considered. Very high } \mathrm{I}_{\mathrm{sp}} \text { (greater than } 750 \mathrm{lb}_{\mathrm{r}} \mathrm{s} / \mathrm{l} \mathrm{b}_{\mathrm{m}} \text { ) is needed to } \\
\text { enable a mass savings over advanced oxygen/hydrogen propulsion. Associated with the potential benefits of high- } \\
\mathrm{I}_{\mathrm{sp}} \text { atomic hydrogen are several challenging problems. Very high magnetic fields are required to maintain the } \\
\text { atomic hydrogen in a solid hydrogen matrix. The magnetic field strength has been estimated to be } 30 \text { kilogauss } \\
\text { ( } 3 \text { Tesla). Also the storage temperature of the propellant is } 4 \mathrm{~K} \text {. This very low temperature will require a large } \\
\text { refrigeration facility for the launch vehicle. The design considerations for a very high recombination rate for the } \\
\text { propellant are also discussed. A recombination rate of } 210 \mathrm{~cm} / \mathrm{s} \text { is predicted for atomic hydrogen. This high } \\
\text { recombination rate can produce very high acceleration for the launch vehicle. Unique insulation or segmentation } \\
\text { to "inhibit" the propellant may be needed to reduce its recombination rate. }\end{array}$} \\
\hline $\begin{array}{l}\text { 17. Key Words (Suggested by Author(s)) } \\
\text { Atomic hydrogen } \\
\text { Free-radial propulsion } \\
\text { Launch vehicles }\end{array}$ & \multicolumn{3}{|c|}{$\begin{array}{l}\text { 18. Distribution Statement } \\
\text { Unclassified-Unlimited } \\
\text { Subject Category } 20\end{array}$} \\
\hline $\begin{array}{l}\text { 19. Security Classif. (of this report) } \\
\text { Unclassified }\end{array}$ & $\begin{array}{l}\text { 20. Security Classif. (of this page) } \\
\text { Unclassified }\end{array}$ & $\begin{array}{c}\text { 21. No. of pages } \\
12\end{array}$ & $\begin{array}{r}\text { 22. Price* } \\
\mathrm{A} 03\end{array}$ \\
\hline
\end{tabular}


